\title{
A Comparative Study to Assess the Relationship of Placental Weight and Fetal Outcome among Normal and Anemic Mothers Admitted in Tertiary Care Hospital Karad
}

\author{
Jyoti R. Dhagale', Jyoti A. Salunkhe ${ }^{*}$, S. V. Kakade², Avinash H. Salunkhe', \\ Vaishali Mohite' ${ }^{1}$ and Ujawala Chopade ${ }^{1}$ \\ 'Krishna Institute of Nursing Sciences, Krishna Institute of Medical Sciences Deemed University Karad, \\ Karad, Satara - 415539, Maharashtra, India; jasalunkhe.salunkhe9@gmail.com \\ ${ }^{2}$ Krishna Institute of Medical Sciences, KIMSDU, Karad - 415539, Maharashtra, India
}

\begin{abstract}
Severe anemia during pregnancy is a potentially hazardous hematological disorder. According to a World Health Organization (WHO) report the global prevalence of anemia among pregnant women is $55.9 \%$. In India, the highest prevalence of moderate anemia was found in Nagaon District (82.7\%) noted by G. S. Toteja et al., in 2006. The present study was aimed to assess the relationship of placental weight and fetal outcome among normal and anemic delivered mothers. The objectives of the study are to assess and compare placental weight and fetal outcome among normal and anemic delivered mothers and to find an association between placental weight and fetal outcome with selected demographic variables in both groups. Quantitative research approach and comparative, descriptive design was used for the study. The study was conducted at Krishna hospital Karad by using Purposive sampling technique on 62 normal and 62 anemic mothers. Descriptive and inferential statistics were used for analysis. Results shows that unpaired t test revealed that mean placental weight of anemic mothers was significantly higher than of normal mothers ( $p<0.05)$. Mean fetal weight of babies delivered to normal mothers was significantly higher than the babies delivered to anemic mothers $(\mathrm{p}<0.05)$ and length of babies delivered to normal mothers was significantly higher than babies delivered to anemic mothers $(\mathrm{p}<0.05)$. There was significant association was found between placental weight of normal mothers and monthly income of family, $(p<0.05)$. The study concludes that correlation between placental weight and birth weight of babies shows significant difference with a positive correlation in both the groups. This means as the placental weight increases the birth weight also increases and vice-versa.
\end{abstract}

Keywords: Anemic Mother, Assess Placental Weight, Fetal Outcome, Fetal Weight

\section{Introduction}

Anemia during pregnancy is most common and considerable health problem in developing countries and it is largely preventable and easily treatable if detected in time. Anemia still continues to be a common cause of mortality and morbidity in India. Anemia depends on some factors like socioeconomic status, dietary habit, and lifestyle, communicable and non communicable diseases ${ }^{1}$.
Anemia affects placenta and fetal outcome dreadfully. Placenta is a developing organ during pregnancy for providing nutrition, oxygen supply for the fetus and to eliminate excretory wastes, acts as protective barrier. If the placenta has got affected due to anemia it adversely affects for the growth of the fetus. Hence a good fetal outcome depends on mothers' health and her diet during antenatal period ${ }^{2}$.

Anemia is a pathological condition which leads to 
loss of placental weight and poor perinatal outcome and it is major public health problem throughout the world. The World Health Organization (WHO) reports estimated that 56 million live in developing countries the most severely affected area is South Asia where as $89 \%$ of pregnant women are anemic in India. Anemia is responsible for $12-28 \%$ of fetal loss, $30 \%$ perinatal death, and $7-10 \%$ of fetal death ${ }^{3}$.

Severe anemia during pregnancy is a potentially hazardous hematological disorder. It is associated with late abortions, prematurity, low birth weight and stillbirths ${ }^{4}$ the sum of which is increased perinatal loss. According to a World Health Organization (WHO) report the global prevalence of anemia among pregnant women is 55.9\%. Anemia in pregnancy is observed more frequently in developing countries. The prevalence of anaemia in South East Asia is around $56 \%$. In India the incidence of anemia in pregnancy has been noted as $40-80 \%{ }^{5}$. The proportion of maternal deaths due to anemia has been estimated in India about $16 \%{ }^{6}$. It also increases the maternal, fetal mortality and morbidity significantly ${ }^{7}$.

The prevalence of anemia among pregnant women and lactating mothers at Maharashtra state is $76 \%$ and $73 \%^{8}$. The prevalence of anemia at Satara district was $45.3 \%$. At Karadtaluka percentage of anemia was 43.4 with more prevalence of moderate anemia in 2 nd and 3 rd trimester $^{10}$. The problem statement of this work- A comparative study to assess the relationship of placental weight and fetal outcome among normal and anemic mothers admitted in tertiary care hospital Karad, Maharashtra, India. Based on the above task we framed the below two objectives.

- To assess and compare placental weight and fetal outcome among normal and anemic delivered mothers.

- To find an association between placental weight and fetal outcome with selected demographic variables in both groups.

\section{Materials and Method}

Quantitative research approach and comparative, descriptive design was used for the study. The dependent variable was placental weight, and independent variable was fetal outcome (birth weight, fetal length, head circumference). The study was conducted at Krishna
Hospital, Karad, Satara district, Maharashtra, India on 124 delivered mothers (group one 62 mothers $\mathrm{Hb}>11$ $\mathrm{gm} / \mathrm{dl}$ and group two 62 mothers $\mathrm{Hb}<11 \mathrm{gm} / \mathrm{dl}$.) by using convenient sampling technique. The sample size was calculated as:

$\mathrm{n}=\frac{\left(\mathrm{SD}_{1}{ }^{2}+\mathrm{SD}_{2}{ }^{2}\right)(1.96+1.645)^{2}}{\left(\mathrm{X}_{1}-\mathrm{X}_{2}\right)^{2}}=62$ in Group $1 \& 62$ in Group 2

The tool was prepared after extensive review of literature and with help of experts to assess the relationship of placental weight and fetal outcome among normal and anemic delivered mothers. The research tool consist of two part

Part A: Performa for collecting socio-demographic data

Part B: Standard electronic weight machine, tap measure and Performa to collect maternal and fetal variables.

\section{Method of Data collection}

Official permission to conduct the study was obtained from the Medical Director, Krishna Hospital and Medical Research Center Karad. Informed consent was obtained from the each subject before collecting data by explaining the purpose of conducting the study and after considering the inclusion and exclusion criteria.

\section{Plan for Data Analysis}

The data were analyzed in the term of objective of the study by using descriptive and inferential statistics.

\section{Results}

Normal mothers 36(58.1\%) of them were between age 2429 yrs, 60(96.8\%) from Hindu religion, 37(59.7\%) from nuclear family, $49(79 \%)$ were consuming mixed type of diet, $16(25.8 \%)$ were having monthly family income between Rs.11,000 to 15,000 and majority 33(53.2\%) were primipara. From anemic mothers $30(48.4 \%)$ of them were between age 24-29yrs, 56(90.3\%) from Hindu religion, $41(66.1 \%)$ from nuclear family, $47(75.8 \%)$ were consuming mixed type of diet, 21(33.9\%) were having monthly family income between Rs. 11,000 to 15,000 and majority $33(53.2 \%)$ were primipara. 
Table 1. Distribution of mothers according to demographic variables in both groups

$\mathrm{N}=102$

\begin{tabular}{|c|c|c|c|c|}
\hline \multirow[t]{2}{*}{ Demographic variables } & \multicolumn{2}{|c|}{ Normal Mothers $\mathrm{Hb} \geq 11 \mathrm{gm} / \mathrm{dl}$} & \multicolumn{2}{|c|}{ Anemic Mothers $\mathrm{Hb}<11 \mathrm{gm} / \mathrm{dl}$} \\
\hline & No & Percentage & No & Percentage \\
\hline \multicolumn{5}{|l|}{ Age in years } \\
\hline $18-23$ & 20 & 32.3 & 27 & 43.5 \\
\hline $24-29$ & 36 & 58.1 & 30 & 48.4 \\
\hline$>30$ & 6 & 9.7 & 5 & 8.1 \\
\hline \multicolumn{5}{|l|}{ Religion } \\
\hline Hindu & 60 & 96.8 & 56 & 90.3 \\
\hline Muslim & 2 & 3.2 & 6 & 9.7 \\
\hline \multicolumn{5}{|l|}{ Type of family } \\
\hline Joint Family & 25 & 40.3 & 21 & 33.9 \\
\hline Nuclear Family & 37 & 59.7 & 41 & 66.1 \\
\hline \multicolumn{5}{|l|}{ Type of diet } \\
\hline Mixed & 49 & 79 & 47 & 75.8 \\
\hline Vegetarian & 13 & 21 & 15 & 24.2 \\
\hline \multicolumn{5}{|l|}{ Monthly family income } \\
\hline$<4000$ - Lower & 2 & 3.2 & 1 & 1.6 \\
\hline 5,000 to 10,000 -Lower middle & 12 & 19.4 & 14 & 22.6 \\
\hline 11,000 to 15,000 -Middle & 16 & 25.8 & 21 & 33.9 \\
\hline 16,000 to 25,000 - Upper & 14 & 22.6 & 14 & 22.6 \\
\hline 26,000 to 29,000 -Upper middle & 11 & 17.7 & 8 & 12.9 \\
\hline$>29,000$ & 7 & 11.3 & 4 & 6.5 \\
\hline \multicolumn{5}{|l|}{ Parity } \\
\hline Primipara & 33 & 53.2 & 33 & 53.2 \\
\hline Multipara & 29 & 46.8 & 29 & 46.8 \\
\hline
\end{tabular}

Table 2. Mean, $\mathrm{SD}, \mathrm{t}$ and $\mathrm{p}$ value of maternal variables in Both the Groups

\begin{tabular}{|l|c|c|c|c|c|c|}
\hline \multirow{2}{*}{ Variables } & \multicolumn{2}{|c|}{ Normal Mothers $\mathbf{H b} \geq \mathbf{1 1} \mathbf{~ g m} / \mathbf{d l}$} & \multicolumn{2}{|c|}{ Anemic Mothers $\mathbf{H b}<\mathbf{1 1} \mathbf{g m} / \mathbf{d l}$} & \multirow{2}{*}{$\mathfrak{t}$ ' value } & \multirow{2}{*}{$\mathbf{p}$ value } \\
\cline { 2 - 5 } & Mean & SD & Mean & SD & & \\
\hline Placental weight $(\mathrm{gm})$ & 459.4 & 74.8 & 512.8 & 89.8 & 3.6 & 0.001 \\
\hline Fetal weight $(\mathrm{kg})$ & 2.84 & 0.45 & 2.48 & 0.47 & 4.22 & 0.001 \\
\hline Fetal length $(\mathrm{cm})$ & 51.15 & 2.7 & 49.21 & 1.87 & 4.63 & 0.001 \\
\hline Head circumference $(\mathrm{cm})$ & 32 & 2.13 & 31.4 & 2.23 & 1.52 & 0.13 \\
\hline Gestational age at delivery(wks) & 39.02 & 1.78 & 38.7 & 1.63 & 1.06 & 0.29 \\
\hline
\end{tabular}

The mean placental weight of anemic mothers was significantly higher than normal mothers $(\mathrm{p}<0.05)$. The mean fetal weight of babies delivered to normal mothers was significantly higher than babies delivered to anemic mothers $(p<0.05)$. The mean fetal length of babies delivered to normal mothers was significantly higher than babies delivered to anemic mothers $(\mathrm{p}<0.05)$. There was no significant difference between GA at delivery (weeks) and mean head circumference of babies delivered and to anemic mothers and normal mothers ( $p>0.05)$.

Table 3. Correlation between placental weight and birth weight of babies $\quad \mathrm{N}=102$

\begin{tabular}{|c|c|c|c|c|c|c|c|c|}
\hline \multirow{2}{*}{ Birth weight } & \multicolumn{4}{|c|}{ Normal Mothers $\mathrm{Hb} \geq 11 \mathrm{gm} / \mathrm{dl}$} & \multicolumn{4}{|c|}{ Anemic MothersHb $<11$ gm/dl } \\
\hline & \multicolumn{2}{|c|}{ LBW $(<2500$ gm $)$} & \multicolumn{2}{|c|}{$\mathrm{NBW}(\geq 2500 \mathrm{gm})$} & \multicolumn{2}{|c|}{ LBW $(<2500 \mathrm{gm})$} & \multicolumn{2}{|c|}{$\mathrm{NBW}(\geq 2500 \mathrm{gm})$} \\
\hline Mean \pm SD & 436.6 & 5.07 & 466. & 76.89 & 492.4 & 38.74 & 539. & 35.57 \\
\hline Unpaired $\mathrm{t}$ test & \multicolumn{4}{|c|}{$\mathrm{t}=1.48, \mathrm{p}=0.15$} & \multicolumn{4}{|c|}{$\mathrm{t}=2.10, \mathrm{p}=0.04^{\star}$} \\
\hline Placental Weight & No & $\%$ & No & $\%$ & No & $\%$ & No & $\%$ \\
\hline$\leq 500 \mathrm{gm}$ & 12 & 80 & 36 & 76.5 & 19 & 54.2 & 10 & 37.1 \\
\hline$>500 \mathrm{gm}$ & 3 & 20 & 11 & 23.5 & 16 & 45.8 & 17 & 62.9 \\
\hline Total & 15 & 24.2 & 47 & 75.8 & 35 & 56.4 & 27 & 43.6 \\
\hline Chi square test & \multicolumn{4}{|c|}{$\chi^{2}=0.07, p=0.78$} & \multicolumn{4}{|c|}{$\chi^{2}=1.82, p=0.18$} \\
\hline
\end{tabular}


Normal Mothers- The mean placental weight of non anemic mothers delivered NBW babies was significantly higher than mean placental weight of non anemic mothers delivered LBW babies $(t=1.48, \mathrm{p}=0.15)$. There was no association between placental weight and birth weight of babies ( $<2500$ gm LBW, $\geq 2500$ gm NBW) born to non anemic mothers ( $\mathrm{p}>0.05)$.

Anemic Mothers- The mean placental weight of anemic mothers delivered NBW babies was significantly higher than mean placental weight of anemic mothers delivered LBW babies $(\mathrm{t}=2.10, \mathrm{p}=0.04)$. There was no association between placental weight and birth weight of babies $(<2500$ gm LBW, $\geq 2500$ gm NBW) born to anemic mothers $(\mathrm{p}>0.05)$.

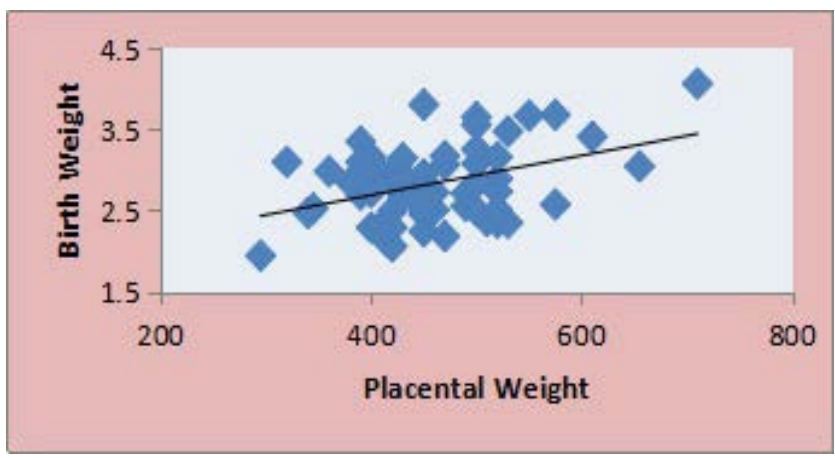

Figure 1. Correlation between placental weight and birth weight of normal mothers.
There was significant correlation between placental weight and birth weight of babies born to normal mothers $(\mathrm{r}=0.40, \mathrm{P}<0.05)$ with a positive correlation in the scatter diagram. This means as the placental weight increases the birth weight also increases and vice-versa.

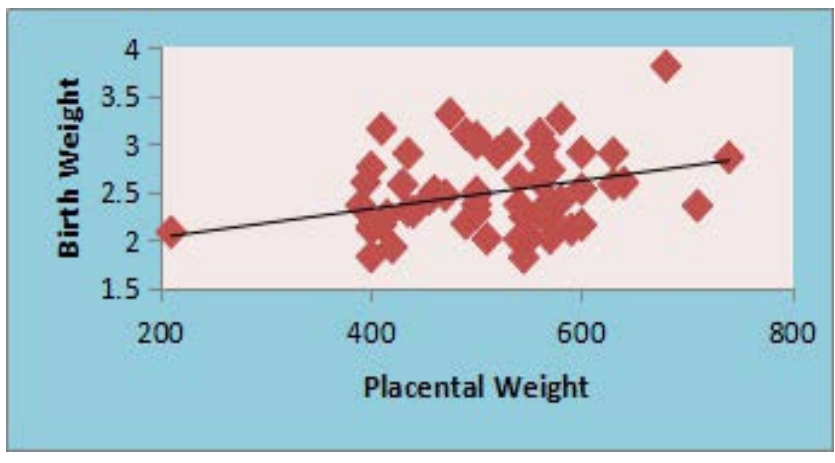

Figure 2. Correlation between placental weight and birth weight for anemic mothers.

There was significant correlation between placental weight and birth weight of babies born to anemic mothers $(\mathrm{r}=0.28, \mathrm{P}<0.05)$ with a positive correlation in the scatter diagram. This means as the placental weight increases the birth weight also increases and vice-versa.

There was no correlation between Placental Weight and Fetal Length of babies born to non anemic and anemic mothers. $(p>0.05)$.

Table 4. Correlation between placental weight and fetal length

$\mathrm{N}=102$

\begin{tabular}{|c|c|c|c|c|c|c|c|c|}
\hline \multirow[t]{2}{*}{ Fetal Length } & \multicolumn{4}{|c|}{ Normal Mothers $\mathrm{Hb} \geq 11 \mathrm{gm} / \mathrm{dl}$} & \multicolumn{4}{|c|}{ Anemic Mothers $\mathrm{Hb}<11 \mathrm{gm} / \mathrm{dl}$} \\
\hline & \multicolumn{2}{|c|}{$\leq 50$} & \multicolumn{2}{|c|}{$>50$} & \multicolumn{2}{|c|}{$\leq 50$} & \multicolumn{2}{|c|}{$>50$} \\
\hline Mean \pm SD & 457.8 & 75.09 & 460 & 75.69 & 509. & 88.79 & & 9.42 \\
\hline Unpaired $t$ test & \multicolumn{4}{|c|}{$\mathrm{t}=0.14, \mathrm{p}=0.89$} & \multicolumn{4}{|c|}{$\mathrm{t}=0.69, \mathrm{p}=0.51$} \\
\hline Placental Weight & No & $\%$ & No & $\%$ & No & $\%$ & No & $\%$ \\
\hline$\leq 500 \mathrm{gm}$ & 21 & 75 & 27 & 79.4 & 25 & 46.3 & 4 & 50 \\
\hline$>500 \mathrm{gm}$ & 7 & 25 & 7 & 20.6 & 29 & 53.7 & 4 & 50 \\
\hline Total & 28 & 45.1 & 34 & 54.9 & 54 & 87.1 & 8 & 12.9 \\
\hline Chi square test & \multicolumn{4}{|c|}{$\chi^{2}=0.17, p=0.68$} & \multicolumn{4}{|c|}{$\chi^{2}=0.03, p=0.85$} \\
\hline
\end{tabular}

Table 5. Correlation between placental weight and head circumference

$\mathrm{N}=102$

\begin{tabular}{|c|c|c|c|c|c|c|c|c|}
\hline \multirow[t]{2}{*}{ Head Circumference } & \multicolumn{4}{|c|}{ Normal Mothers $\mathrm{Hb} \geq 11 \mathrm{gm} / \mathrm{dl}$} & \multicolumn{4}{|c|}{ Anemic Mothers $\mathrm{Hb}<11 \mathrm{gm} / \mathrm{dl}$} \\
\hline & \multicolumn{2}{|c|}{$\leq 34$} & \multicolumn{2}{|c|}{$>34$} & \multicolumn{2}{|c|}{$\leq 34$} & \multicolumn{2}{|c|}{$>34$} \\
\hline Mean \pm SD & 446.7 & 2.92 & 533. & 98.71 & 505. & 75.41 & 594 & 08.59 \\
\hline Unpaired $\mathrm{t}$ test & \multicolumn{4}{|c|}{$\mathrm{t}=2.54, \mathrm{p}=0.03^{\star}$} & \multicolumn{4}{|c|}{$\mathrm{t}=1.77, \mathrm{p}=0.14$} \\
\hline Placental Weight & No & $\%$ & No & $\%$ & No & $\%$ & No & $\%$ \\
\hline$\leq 500 \mathrm{gms}$ & 53 & 100 & 0 & 0 & 57 & 100 & 0 & 0 \\
\hline$>500 \mathrm{gms}$ & 0 & 0 & 9 & 100 & 0 & 0 & 5 & 100 \\
\hline Total & 53 & 85.5 & 9 & 14.5 & 57 & 91.9 & 5 & 8.1 \\
\hline Chi square test & \multicolumn{4}{|c|}{$\chi^{2}=6.55, p=0.01^{\star}$} & \multicolumn{4}{|c|}{$\chi^{2}=157, p=0.21$} \\
\hline
\end{tabular}


Normal Mothers - There was association between placental weight and head circumference of babies born to normal mothers. The babies having placental weight $\leq 500$ gm were having significantly lower head circumference $\leq$ $34(\mathrm{p}=0.01)$.

Anemic Mothers - There was no association between placental weight and head circumference of babies born to anemic mothers ( $\mathrm{p}>0.05)$.

Association between Demographic Variables and Placental weight - There was significant association was found between placental weight of non anemic mothers and monthly family income $(\mathrm{p}<0.001)$ and there was no significant association found between other demographic variables and placental weight. There was no significant association was found between placental weights with demographic variables of anemic mothers.

\section{Discussion}

In the present study the mean placental weight of anemic mothers (512.8 gms) was significantly higher than mean placental weight of normal mothers (459.4 gms) $(\mathrm{p}<0.05)$. Placental hypertrophy could occur because the mother suffering from anemia, still it was considered as normal category. The similar findings were noted by Sitti Patimah et al., at Indonesia researcher found that the average of placental weight was $587 \mathrm{~g}$, it was still considered in the normal category. Another researcher Adebami OJ et al., in South western Nigeria reported that an average placenta weight was $565.2 \mathrm{~g}^{11}$. The placenta weight disproportionately (placental hypertrophy), indicated the possibility of an adaptive response to bad intrauterine environment. Placental hypertrophy could occur because the mother suffering from anemia, smoking or exposure to cigarette smoke, and low socioeconomic status.

In the present study the mean fetal weight of babies delivered to normal mothers was significantly higher than mean fetal weight of babies delivered to anemic mothers $(\mathrm{p}<0.05)$. The similar findings were noted by Sitti Patimah et al., at Indonesia researcher found that placental weight correlated with birth weight infants significantly. In another study by Thame et al., ${ }^{12}$ and Salafia et al., ${ }^{13}$ noted that placental size was correlated with birth size. Many studies in Norway shown that more than 200,000 births reported the Medical Birth Registry of Norway showed a placental weight relationship with birth weight ${ }^{14}$ In another study conducted by Asgharnia et al., ${ }^{15}$ and Risnes et al., ${ }^{16}$ that there was a relationship of placental weight to birth weight infants $(\mathrm{p}<0.0001$, and $\mathrm{p}=0.001)$, as well as the results Alwasel et al. ${ }^{17}$ noted that placental weight correlated with birth weight $(\mathrm{r}=0.34)$. Baby were born with placental weight $(\geq 500 \mathrm{~g})$ had an average birth weight higher $472 \mathrm{~g}$ than birth weight baby with light placenta.

Mean fetal length of normal mothers $(51.15 \mathrm{~cm})$ was significantly higher than mean fetal length of anemic mothers (49.21) $(\mathrm{p}<0.05)$. The similar findings were noted by Sitti Patimah et al., at Indonesia researcher found that the average of body length of a baby's soon after birth showed $1.2 \mathrm{~cm}$ taller than baby born with mild placenta $(<500 \mathrm{~g})$. It showed that placental weight had a significant role to the growth of the fetus ${ }^{18}$.

\section{Conclusion}

- There was correlation between placental weight and birth weight of babies born to non anemic and anemic mothers and shows significant difference with a positive correlation.

- The significant association was found between placental weight and income of family of normal mothers, $(\mathrm{p}<0.05)$.

\section{References}

1. Jaya M, SujataT. A study assesses the effectiveness of nutritional intervention among women anemia in selected village Thiruvallur District. Nightingale Nursing Times. 2008 July; 4(4):9-11

2. Krishnamenon MK, Palaniappa B, Mudaliar, Menon. Clinical obstetrics. 9th ed. New Delhi; Orient Longman Ltd; 2004. p. 23-5

3. Shama JB. Nutritional anemia in pregnancy. Obst Gynecol. 2007 Jan; 12(1):17-8.

4. Resnik R. Intrauterine growth restriction. Obstetrics and Gynecology. 2002; 99(3):490-6. Crossref

5. Bansal A. Study on prevalence of anaemia in pregnancy in rural population of Pilkhuwa, Hapur U.P. International Journal of Contemporary Microbiology. 2015; 1(1). Crossref

6. Sujeevani M, Nynke B. Anaemia in pregnancy in Malawi- A review. Malawi Medical Journal. 2006 Dec; 18(4):160-74.

7. Basu SK. Anaemia in pregnancy. GM Modi Hospital. Available from: Crossref

8. Nimmathota A, Indrapal IM, Nagalla B, Rachkula H, Rao KM, Avula L. Prevalence of anaemia among different phys- 
iological groups in the rural areas of Maharashtra. Indian Journal of Community Health. 2014; 26(3).

9. Goyal P, Potdar VR, Reddy BR. Hematological profile of nutritional anaemia among adolescent girls in rural area around Karad, District- Satara, Maharashtra. Journal of Medical Sciences and Clinical Research. 2016; 4(12).

10. Bivalkar NY, Wingkar KC, Joshi AG, Jagtap S. Study of anemia and it's epidemiological determinants in pregnant women. International J of Healthcare and Biomedical Research. 2015; 3(2):140-5.

11. Adebami OJ, Owa JA, Oyedeji GA. Factor associated with placenta weight and placental weight/birtweight percent (placental ratio) among mothers in Ilesa, Southwesttern Nigeria. Int J Trop Med. 2007; 2(2):68-73.

12. Thame M, Osmond C, Bennett F, et al. Fetal growth is directly related to maternal anthropometry and placental volume. Eur J ClinNutr. 2004, 58(6):894-900. Crossref PMid:15164110

13. Salafia CM, Charles AK, Maas EM. Placenta and fetal growth restriction. Clin Obstet Gynecol. 2006; 49(2):23656. Crossref PMid:16721104
14. Thompon JM, Irgens LM, Skjaerven R, Rasmussen S. Placental weight percentile curves for singleton deliveries. BJOG. 2007; 114(6):715-20. Crossref PMid:17516963

15. Asgharnia M, Esmailpour N, Poorghorban M, Atrkar-Roshan Z. Placental weight and its association with maternal and neonatal characteristics. Acta Med Iran. 2008; 46(6):467-72.

16. Risnes KR, Romundstad PR, Nilsen TIL, Eskild A, Vatten LJ. Placental weight relative to birth weight and longterm cardiovascular mortality: findings from a cohort of 31.307 men and women. Am J Epidemiol. 2009; 170(5):622-31. Crossref PMid:19638481

17. Alwasel SH, Abotalib Z, Aljarallah JS, Osmond C, Alkharaz SM, Alhazza IM, Badr G, Barker DJ. Changes in placental size during ramadan. Placenta. 2010; 31(7):607-10. Crossref PMid:20621763

18. Lo YF, Jeng M, Lee YS, Soong WJ, Hwang B. Placental weight and birth characteristics of healthy singleton newborns. Acta Paediatr Taiwan. 2002; 43(1):21-25. PMid:11890222 